\title{
Ensino de frações para adolescentes com deficiência visual ${ }^{*}$
}

\author{
Teaching fractions to visually impaired adolescents
}

\author{
Ailton Barcelos da Costa ${ }^{1}$ \\ https://orcid.org/0000-0002-3260-5392 \\ Maria Stella Coutinho de Alcântara Gil ${ }^{2}$ \\ https://orcid.org/0000-0003-4375-3232 \\ Nassim Chamel Elias ${ }^{2}$ \\ https:// orcid.org/0000-0003-4197-623X
}

\begin{abstract}
Resumo: O estudo teve o objetivo de ensinar frações unitárias e não unitárias para três adolescentes com deficiência visual, empregando tentativas discretas, instruções orais e reforçamento diferencial em um delineamento do tipo A-B com follow up. O procedimento consistiu do levantamento do repertório de entrada, intervenção e sondas de aprendizagem. Na intervenção, empregaram-se materiais concretos e instruções orais com e sem dicas. A manutenção da aprendizagem foi avaliada 30 dias após o encerramento da intervenção. Na linha de base, os participantes identificaram igualdade, diferença e metade de quatro e seis peças. $\mathrm{Na}$ intervenção, as atividades relativas à metade/terço/quarto de quantidade superior a dez unidades foram realizadas ao final do período. A verificação da manutenção da aprendizagem foi bem-sucedida para os participantes. A adaptação de materiais concretos e instruções permitiram o domínio de tarefas de produção de frações.
\end{abstract}

Palavras-chave: Ensino de frações. Deficiência visual. Matemática inclusiva. Educação especial.

\begin{abstract}
The study aimed to teach unit and non-unit fractions for three adolescents with visual impairment, using discrete attempts, oral instructions and differential reinforcement in an A-B design follow-up. The procedure consisted of baseline repertoire assessment, intervention, and learning probes. In the intervention, concrete materials and oral instructions, with or without prompts, were employed. Maintenance was assessed 30 days after the closure of intervention. At baseline, participants identified equality; difference and half of four and six pieces. In the intervention, the activities related to the half / third / fourth parts of more than ten units were done at the end of the period. Verification of learning maintenance was successful for the participants. The adaptation of concrete materials and instructions led to command of fraction production.
\end{abstract}

Keywords: Fraction teaching. Visual impairment. Inclusive mathematics. Special education.

\footnotetext{
* O artigo é parte da dissertação de mestrado do primeiro autor, sob orientação da segunda autora, com a colaboração nas análises e elaboração do manuscrito pelo terceiro autor.

${ }^{1}$ Universidade Federal de São Carlos (UFSCar), Centro de Educação e Ciências Humanas, Programa de Pós-

Graduação em Educação Especial, São Carlos, SP, Brasil. E-mail: ailton.barcelos@ufscar.br

${ }^{2}$ UFSCar, Departamento de Psicologia, São Carlos, SP, Brasil.
} 


\section{Introdução}

O conhecimento de habilidades matemáticas é considerado essencial para uma vida independente, pois indivíduos com formação matemática podem resolver diversos problemas da vida diária, como manipulação de dinheiro, contagem e medição (ROSENBLUM; HERZBERG, 2011). Além disso, pode-se afirmar que a matemática está entrelaçada com as atividades da vida diária e com as situações sociais. Os conceitos matemáticos básicos são considerados essenciais em vários programas de formação profissional e educacional (KLINGENBERG; FOSSE; AUGESTAD, 2012). No entanto, no Brasil, verificou-se que $84,48 \%$ dos alunos do $5^{\circ}$ ano do Ensino Fundamental não tinham atingido o aprendizado adequado em matemática, segundo o Sistema de Avaliação da Educação Básica (BRASIL, 2018).

A superação dos entraves à formação matemática ainda mais desafiadora para as pessoas com deficiência visual. $\mathrm{O}$ ensino de tarefas de matemática para pessoas cegas ou com baixa visão, segundo Fernandes e Healy (2010), requer o uso de tecnologia assistiva ou material adaptado à inspeção tátil. $\mathrm{O}$ termo material adaptado à inspeção tátil refere-se à adaptação de elementos visuais ao acesso pelo tato (DEL CAMPO, 1996). A expressão tecnologia assistiva vem sendo utilizada para tratar de recursos e serviços que contribuem para proporcionar ou ampliar habilidades funcionais de pessoas com deficiência, e para promover vida independente e inclusão (SANTOS et al., 2017).

Fernandes e Healy (2010) afirmam que na formação matemática, além do material adaptado, os procedimentos de ensino precisam ser planejados de modo a atender as necessidades educacionais dessa população. Del Campo (1996) sustenta que a falta de visão não impossibilita o acesso aos aspectos matemáticos da realidade, apenas modifica-os. Em outras palavras, a didática da matemática dirigida aos alunos com cegueira ou baixa visão tem um objetivo concreto e bem diferenciado: a adequada tradução das formas visuais à linguagem matemática. Isso significa que, sem o suo de materiais concretos, esses alunos teriam grande dificuldade de acompanhar a matemática nos anos iniciais do Ensino Fundamental e na escolarização subsequente (REILY, 2004).

Para Lewis (2003), à medida que a pessoa aprende a discriminar os objetos via tato, é preciso introduzir, progressivamente, a linguagem que ensina o reconhecimento desses pelo nome. Dito de outro modo, no processo de aprendizagem tátil, a linguagem é igualmente importante, uma vez que cria condições para outros níveis de abstração e capacidade mais elaborada de discriminar e reconhecer símbolos, de modo que o indivíduo possa reconhecer os sinais do sistema braile que pressupõem um alto nível de abstração e associação cognitiva.

O International Council for Education of People with Visual Impairment (ICEVI) (MANI et al., 2005), que trata das estratégias de ensino de matemática no Ensino Fundamental e Médio para pessoas com deficiência visual, propõe o uso do soroban como estratégia principal para o ensino de matemática, ensino das operações básicas e frações. Entretanto, considera-se também que o ensino de frações e suas operações pode ser feito via código Braille Nemeth para Matemática e Ciências. O código Nemeth, para Kapperman e Sticken (2002), é uma versão especial de braile para matemática e pode ser usado para a transcrição de matemática, álgebra e cálculos.

Os estudos sobre o ensino de repertórios matemáticos para pessoas com cegueira ou baixa visão, do ponto de vista da Análise do Comportamento, são bastante reduzidos, apesar 
da relevância que Skinner atribuiu às questões de ensino e aprendizagem (SKINNER, 1972) e da ênfase conferida ao tema por educadores e pesquisadores de outras abordagens (DEL REY, 2009). Um aspecto em comum a essa produção é o da importância do ensino de tarefas e habilidades matemáticas fundamentais, consideradas pré-requisitos para o desenvolvimento de outros repertórios matemáticos, como o de resolução de problemas (HAYDU; COSTA; PULLIN, 2006). Por exemplo, Henklain, Carmo e Haydu (2017) apresentaram diversas contribuições da Análise do Comportamento para a Educação em relação ao ensino de habilidades matemáticas básicas no ensino de frações para diferentes populações, inclusive, para pessoas com desenvolvimento atípico.

Em relação aos repertórios matemáticos, Carmo (2000) os define como os comportamentos com probabilidade de serem emitidos em contingências que envolvam números falados ou escritos, numerosidades, dígitos, problemas matemáticos e de cálculo etc. Cada uma das contingências, indicadas pelo autor, implica o manejo de conjuntos de conceitos que devem estar suficientemente estabelecidos para o domínio do comportamento matemático.

Quando se fala do processo de formação de conceitos, destaca-se que

[...] o processo de formação de conceitos envolve a formação de classes entre os estímulos que funcionam como discriminativos - o responder não ocorre sob controle de um estímulo, mas sob controle de uma classe de estímulos. O processo subjacente à formação de conceitos consiste, por um lado, na ocorrência de respostas generalizadas, demonstradas pelo responder semelhante diante de diversos estímulos (membros de uma mesma classe) e, por outro lado, no responder discriminado entre múltiplas classes de estímulos. A discriminação entre as diferentes classes de estímulos (cada uma controladora de respostas conceituais específicas), demonstrada pelo responder diferencial diante de cada classe, resultaria da interação entre essas diversas classes de estímulos (CANOVAS, 2010, p. 9).

A discriminação entre as diferentes classes de estímulos, cada uma controladora de respostas conceituais específicas, demonstrada pelo responder diferencial diante de cada classe, resultaria da interação entre essas diversas classes de estímulos (CANOVAS, 2010).

Para a análise do comportamento matemático, o ensino de matemática considera uma rede de relações entre estímulos e entre estímulos e respostas, estabelecendo as condições para a ocorrência de desempenhos verbais e de outros desempenhos cognitivos complexos, como a resolução de problemas aritméticos e uso de frações (RIBEIRO; ASSIS; ENUNO, 2007; SANTOS et al., 2014). O conceito de fração também é parte de uma rede de relações. Diferentes contingências estão relacionadas aos diversos desempenhos que podem ser agrupados sob a expressão aprender frações, como separar um conjunto de peças em subconjuntos, grafar a representação de uma fração da maneira convencionalmente solicitada (1/2; $1 / 3$ etc.), escrever o algoritmo que permite somar, multiplicar ou dividir frações e muitas outras possibilidades de desempenho para a relação todo/partes estão reunidas na expressão aprender frações.

O termo fração pode ser definido matematicamente como a relação entre partes selecionadas e o total de partes em que um inteiro (a unidade) foi dividido. Dito de outro modo, um número fracionário consiste no quociente de dois números naturais, no qual o divisor é 
diferente de zero, sendo representado por: $\mathrm{a} / \mathrm{b}, b \neq 0$, para $a$ e $b$ inteiros (VERNEQUE, 2011). Esse conceito deveria ser ensinado a partir do $4^{\circ}$ ano do Ensino Fundamental (BRASIL, 2010).

Para Lopes (2008), as frações são consideradas um megaconceito constituído por diferentes subconceitos, aquilo que se pode chamar de interpretações do conceito. Para Lopes (2008), as frações são consideradas um megaconceito constituído por diferentes subconceitos, aquilo que se pode chamar de interpretações do conceito. Fração, por sua vez, pode ser composta da relação parte-todo (ocorre quando se divide o todo em partes com a mesma medida), quociente (ocorre quando se tem uma situação de repartir), razão (ocorre quando se tem uma comparação entre a parte e o todo) e a fração como operador (ocorre quando se tem uma sucessão de divisões e multiplicações aplicadas a uma unidade).

O ensino de frações, tradicionalmente oferecido em sala de aula, é descrito por Silva, Canosa e Campos (2016). Esse modo de ensino consiste na apresentação das definições na lousa, juntamente com exemplos que exigem que o aprendiz enxergue. Os exemplos mostram desenhos de bolos, círculos, triângulos, quadrados, lápis, frutas diversas e bichinhos parcialmente pintados, representando-as. Ou seja, o professor apresenta as tarefas com frações e solicita que os alunos pintem partes de figuras, o que é inviável para o ensino de alunos com deficiência visual.

Quando se trata do ensino de frações para participantes videntes é importante recuperar a pesquisa de Verneque (2011) que realizou um estudo sobre o ensino de relações condicionais entre representações de frações pictóricas (uma figura com retângulos pintados) e numéricas (por exemplo, 1/3). Os participantes foram 60 alunos do $7^{\circ}$ ano do Ensino Fundamental que realizaram tarefas para a formação de classes de frações equivalentes, expansão das classes com novas formas pictóricas e novos elementos matematicamente equivalentes e novas classes de frações não utilizadas durante o treino. Os resultados indicaram que houve a generalização do repertório na constituição de novas classes. O procedimento e os resultados obtidos apontaram para a importância da elaboração de estratégias de ensino que favoreçam os diferentes tipos de comportamentos novos envolvidos nas tarefas com frações equivalentes.

Em uma direção similar, Santos et al. (2014) investigaram o efeito do treino de relações condicionais entre estímulos fracionários na forma de figuras e na forma numérica e entre estímulos numéricos e frações numéricas. Os participantes foram 20 alunos com desenvolvimento típico, com idade entre 11 e 13 anos, expostos ou não ao treino de composição (cópia) sobre a formação de classes de equivalência com estímulos fracionários. Os participantes foram divididos em dois grupos (controle e experimental) e passaram por treinos e testes de relações condicionais, entretanto só o experimental foi exposto ao treino de composição de frações antes dos treinos das relações condicionais. Os dois grupos fizeram apenas as avaliações inicial e final.

Os participantes foram bem-sucedidos nas tarefas apresentando desempenhos que mostraram a formação de classes de equivalência com estímulos fracionários numéricos e em figuras, níveis discretos de expansão dessas classes e a possibilidade de generalização da resposta para novas situações. Não houve, entretanto, evidência de que o treino de composição facilitou a aprendizagem das tarefas de proporção. 
Em relação ao ensino de frações para aprendizes com deficiência visual, um estudo realizado por Trask-Tyler, Grossi e Heward (1994) mostrou que participantes com déficits visuais e intelectuais podem aprender tarefas nas quais o conceito de fração está subjacente, embora não se constitua em tarefa dos aprendizes. Os autores trabalharam com três jovens adultos com deficiência visual e intelectual, com idades entre 17 e 21 anos. Eles utilizaram instruções verbais e orientação física para ensinar os estudantes a preparar três receitas diferentes, usando instruções gravadas em fitas com um sistema de áudio que poderia ser operado pelos próprios participantes. Foi adotado o delineamento de linha de base múltipla entre comportamentos (receitas) para determinar como cada participante melhorava na preparação de receitas. Dentre as instruções verbais, foi solicitado aos participantes que enchessem um copo com 1/4 de água e depois enchessem o mesmo copo com $2 / 4$ de óleo. Os resultados mostraram que os participantes aprenderam a usar sistemas de áudio, operados por eles mesmos, levando-os a aprenderem a seguir receitas na preparação de alimentos. Houve também a generalização para receitas não ensinadas diretamente. Dessa forma, esse estudo mostrou a eficácia de instruções verbais para o ensino de uma determinada competência para pessoas com deficiência visual.

Os estudos de Verneque (2011) e Santos et al. (2014) foram realizados com estudantes que tinham visão íntegra e foram bem-sucedidos em oferecer condições de aprendizagem de tarefas relacionadas ao conceito de fração. Ambos tiveram em comum o ensino de frações usando relações entre frações pictóricas (a fração representada por uma figura) e numéricas (a fração representada por uma relação numérica), em tentativas discretas e de escolha de acordo com o modelo (MTS), com uso de reforçamento diferencial. O estudo de Trask-Tyler, Grossi e Heward (1994) mostrou a eficácia do uso de intervenção comportamental com instruções verbais no ensino de novos repertórios aos participantes com deficiência visual.

Em relação ao planejamento do ensino e da avaliação de comportamentos conceituais numéricos, pode-se recorrer a um procedimento clássico - o procedimento de escolha de acordo com o modelo (matching-to-sample, MTS), como uma tática para estabelecer redes de relações que envolvam estímulos numéricos (CARMO, 2000; HENKLAIN; CARMO; HAYDU, 2017). Nesse procedimento, um estímulo modelo é apresentado ao participante e após a emissão de uma resposta de observação ao modelo são apresentados dois ou mais estímulos de comparação. Em situação de ensino, a resposta ao estímulo de comparação produz consequências diferenciais para acertos e erros (NUNES; ASSIS, 2012; SANTOS et al., 2014; VERNEQUE, 2011).

Considerando o exposto, o presente estudo teve o objetivo de ensinar frações unitárias e não unitárias para três adolescentes com deficiência visual, empregando o ensino por tentativas discretas, instruções orais e reforçamento diferencial em um delineamento do tipo A-B com follow up. Tentativas discretas podem ser definidas como oportunidades sistemáticas e estruturadas de resolver problemas simples (imitação motora) ou complexos (problemas matemáticos). Tais tentativas iniciam-se com a apresentação de instruções e/ou materiais, seguidas pela resposta do aluno e da apresentação de consequências diferenciais para acertos e erros. Adicionalmente, os erros implicam a introdução de dicas ou ajudas para garantir o responder correto nas tentativas seguintes. 


\section{Método}

\section{Participantes}

Participaram da pesquisa três estudantes, dois homens e uma mulher, da escola pública de uma cidade de médio porte do Estado de São Paulo. Os participantes foram identificados por um código alfa-numérico composto pela letra P, seguida da letra "o" ou "a" para designar, respectivamente, os homens e a mulher, seguida do numeral correspondente à idade, como segue: Po14, Po16 e Pa18. Os participantes Po14 e Pa18 tinham diagnóstico de cegueira congênita, recorriam à bengala para os deslocamentos e eram proficientes em braile. O participante Po16 tinha baixa visão congênita. Po14 e Po16 estavam no $8^{\circ}$ ano do Ensino Fundamental e Pa18 cursava o $3^{\circ}$ ano do Ensino Médio. Os professores de matemática e a direção das escolas em que os participantes estavam matriculados relataram que eles tinham grande atraso em relação ao conteúdo de matemática e que demonstravam dificuldade em sala de aula, sem oferecerem mais detalhes sobre o desempenho dos estudantes.

\section{Materiais}

Foram usados quatro protocolos de registro de respostas em diferentes tarefas: (i) registro da avaliação do repertório de quantidades discretas; (ii) registro do repertório de meio e de terço; (iii) registro do desempenho no ensino de frações unitárias e iv) registro do ensino de frações não unitárias.

Para a realização das tarefas, foi utilizada uma caixa de exposição quadrada, de $20 \mathrm{~cm}$ de lado e cinco cm de altura, sem um dos lados. A caixa foi confeccionada em papelão resistente, servindo de delimitação do material exposto e era posicionada sobre a mesa, em frente ao participante. Os objetos/estímulo foram arranjados dentro da caixa para serem manuseados pelo participante.

O material utilizado foi composto por brinquedos ou suas peças e por peças de material pedagógico, como Escala Cuisenaire ${ }^{\circledR}$, brinquedo Monta Fácil ${ }^{\circledR}$, bolinhas de isopor de cinco $\mathrm{cm}$ de raio, bolinhas de pingue-pongue de raio de três $\mathrm{cm}$, bolinhas de vidro de um $\mathrm{cm}$ de raio, brinquedo Monta Fácil ${ }^{\circledR}$ encaixado, massa de modelar e o Círculo de Frações Adaptado.

Para a finalidade do estudo, foi construído o Círculo de Frações Adaptado composto por um círculo de papelão e diversas porções do círculo recortadas de modo a serem subdivididas em duas, três, quatro e cinco partes, todas com raio de cinco cm, e uma peça com oito partes, com raio de oito cm (Figura 1). Seguindo as recomendações de Del Campo (1996), cada parte do círculo foi superposta com uma textura diferente com o uso de tecidos variados e polímeros colados em uma base de papelão. 
Figura 1 - Círculos de frações adaptados

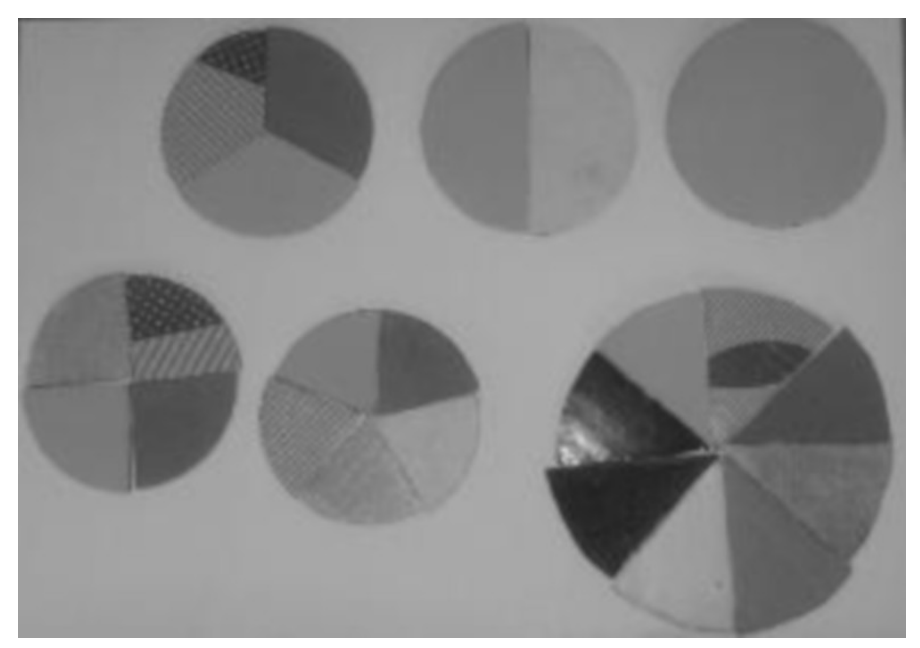

Fonte: elaborado pelos autores a partir de Del Campo (1996).

\section{Coleta de dados}

A coleta de dados foi realizada durante três meses, com dois encontros semanais de aproximadamente 25 minutos de duração cada. Todos os encontros foram gravados com uma câmera digital e as respostas dos participantes foram registradas nos protocolos previamente organizados. Na coleta de dados foi realizado o levantamento do repertório de entrada, a fase de ensino, as sondas de aprendizagem e de verificação de manutenção da aprendizagem (follow up) com um único participante (Po16).

De acordo com Hochman et al. (2005), a utilização do follow up em estudos estabelece uma sequência temporal de observações entre uma intervenção inicial, uma ausência dessa e uma intervenção final, destinando-se a estudar um processo ao longo do tempo.

\section{Procedimentos Éticos}

Após a aprovação da pesquisa no Conselho de Ética em Seres Humanos da Universidade Federal de São Carlos (UFSCar), com o parecer número 121.565/2012, todos os procedimentos éticos foram seguidos. O Termo de Consentimento Livre e Esclarecido foi assinado pelos pais ou responsáveis e o Termo de Assentimento foi assinado pelos participantes.

\section{Levantamento de Repertório de Entrada}

Dois blocos de tarefas, cada um com oito tentativas, foram realizados para medir noções de igualdade e diferença (cinco tentativas) e noções de frações unitárias de metade e um terço (três tentativas).

No primeiro bloco, os participantes deveriam identificar igualdade ou diferença entre objetos em tentativas de escolha de acordo com o modelo atrasado. Pedia-se para os 
participantes identificarem igualdade ou diferença entre: (i) uma peça de base quadrada do brinquedo 'Monta Fácil' e uma bola de isopor de raio de cinco centímetros; (ii) uma bola de isopor de raio de cinco centímetros e uma bola de ping-pong de raio de três centímetros; (iii) duas barras Cuisenaire de dez centímetros de comprimento cada; (iv) uma peça de base quadrada do brinquedo Monta Fácil e uma bola de gude de raio de um centímetro; e, (v) duas barras Cuisenaire de cinco centímetros de comprimento cada. Um objeto/estímulo era oferecido para manuseio por 20 segundos e, em seguida, o outro estímulo era manuseado também por 20 segundos; então, o pesquisador perguntava "Essas peças são iguais ou diferentes?”. Os participantes deveriam informar se as peças manuseadas eram iguais ou diferentes. Cada resposta produzia como consequência uma informação que indicava se foi um acerto ou um erro e a tentativa subsequente era iniciada.

No segundo conjunto de tarefas, os participantes deveriam identificar frações de metade e um terço. As peças eram deixadas à disposição do participante, na caixa de $20 \mathrm{~cm}$ de lado por cinco cm de altura, para que ele pudesse manipular por, no máximo, 20 segundos. Em seguida, era apresentada a instrução oral "Você pode me entregar metade [ou um terço] das peças?”. O participante deveria pegar a parte solicitada e entregar ao pesquisador. Essa resposta produzia como consequência uma informação que indicava se foi um acerto ou um erro e a próxima tentativa era apresentada. Foi solicitado a cada participante que identificasse: (i) a metade de quatro peças de base quadrada do brinquedo Monta Fácil; (ii) a metade de seis barras Cuisenaire de cinco centímetros cada; e, (iii) um terço de seis barras Cuisenaire de cinco centímetros cada.

\section{Procedimento}

\section{Tarefas de Ensino}

O ensino foi realizado em oito encontros, dois encontros semanais em dias diferentes e não consecutivos. No início de cada encontro, o participante era informado que faria atividades com frações. As atividades eram compostas por tentativas discretas. Uma tentativa típica consistia na apresentação de um determinado número de peças colocado dentro da caixa de exposição e de uma instrução. $\mathrm{Na}$ instrução informava-se que havia peças disponíveis e solicitava-se que o participante examinasse o material com as mãos. Terminada a exploração tátil, em uma segunda instrução, solicitava-se a seleção de uma fração das peças, por exemplo: "Você pode me entregar metade [ou um terço, ou três quartos etc.] dessas peças?".

Em cada uma das tentativas, o participante manuseava as peças e informava que tinha a resposta pronta. A resposta do participante (peças na caixa de exposição) poderia ser registrada como uma de três possibilidades apresentadas após solicitação do pesquisador e manuseio do material: (i) acerto, as peças correspondiam à instrução; (ii) erro, as peças eram diferentes do previsto; ou, (iii) acerto mediado, as peças correspondiam ao esperado após dica verbal oral.

A resposta correta correspondia à seleção e entrega pelo participante da parte equivalente à fração apresentada na instrução oral. Havia consequências diferenciais para acertos e erros. Os acertos eram seguidos de elogios, da organização e apresentação do material para a próxima tentativa. 
Os erros eram seguidos de uma nova tentativa com a mesma estrutura e instrução da tentativa em que o erro ocorreu, mas com outro material. Em outras palavras, era solicitada, com a instrução padrão, a seleção da mesma fração de peças de material diferente daquelas apresentadas na tentativa anterior. Nesse caso, o pesquisador fazia perguntas e dava instruções, como para o caso de solicitação para achar um terço de nove peças do brinquedo Monta Fácil: "Eu quero que você ache um terço dessas peças. Você consegue dividir essas peças em trếs montinhos iguais?"; "Os montinhos estão iguais mesmo? Você pode contar cada montinho para ver se estão iguais?"; "Você percebeu que os montinhos estão iguais. Agora me entregue um montinho desses. Esse montinho com três peças é um terço das peças".

Em seguida, a tentativa em que o erro ocorreu era reapresentada, ou seja, o pesquisador dava instruções, como "Agora faz, de novo. Entregue para mim um terço das peças que estão na sua frente".

Diante do acerto, a resposta era seguida por elogios e a tentativa seguinte era apresentada. Diante de novo erro, outro exemplo era oferecido com material ainda não apresentado para aquela instrução.

\section{Ensino das Frações Unitárias}

A fase de ensino iniciou-se com frações unitárias. Foram aplicadas 55 tentativas que diferiam em relação aos materiais e/ou à fração unitária apresentada na instrução. As frações utilizadas foram metade, um terço, um quarto, um quinto e um sexto. O critério de aprendizagem estabelecido foi de $80 \%$ de acertos independentes (sem dicas ou ajudas).

\section{Sonda de Aprendizagem e Follow Up com Frações Unitárias}

Ao final do procedimento de ensino de frações unitárias foram realizadas 21 sondas de aprendizagem. As primeiras oito tentativas utilizaram o material Escala Cuisenaire. Nas três tentativas iniciais foram usadas 12 peças do material, sendo solicitado que o participante entregasse, respectivamente, metade, um terço e um quarto das peças para o pesquisador. Em seguida, foi solicitado um quinto de 10 peças, seguido de um quarto e um quinto de 20 peças, e de um terço e um sexto de 18 peças.

Nas tentativas 9 e 10 foi utilizado o material Círculo de Frações Adaptado, usando oito peças do material, sendo solicitado que o participante entregasse metade e um quarto das peças para o pesquisador. Na tentativa 11 foi solicitado um terço do círculo com três peças.

Nas tentativas 12 e 13 foram utilizadas 15 peças do material Monta Fácil e foi solicitado que o participante entregasse, respectivamente, um terço e um quinto das peças para o pesquisador.

Nas tentativas 14 e 15 foram utilizadas bolinhas de gude, sendo solicitado que o participante entregasse um terço de nove bolinhas e um quarto de oito bolinhas para o pesquisador, respectivamente.

Nas tentativas 16, 17 e 18 foram usadas 12 peças do material Monta Fácil, sendo solicitado que o participante entregasse, respectivamente, metade, um terço e um quarto das peças para o pesquisador. Nas tentativas 19, 20 e 21 foi solicitado um quinto de 15 peças, um quarto de 16 peças e um sexto de 12 peças, respectivamente. 
Após 30 dias da aplicação das sondas de aprendizagem, foram aplicadas as sondas de follow up com as mesmas tentativas das sondas de aprendizagem.

\section{Ensino das Frações Não Unitárias}

Após o follow up com frações unitárias, foram introduzidas as tarefas de ensino com frações não unitárias. Foram aplicadas 24 tentativas que diferiam em relação aos materiais e/ ou à fração não unitária apresentada na instrução. As frações utilizadas foram dois terços, três quartos, dois quintos, três quintos, quatro quintos e cinco sextos $(2 / 3,3 / 4,2 / 5,3 / 5,4 / 5$ e $5 / 6$ ). O critério de aprendizagem estabelecido foi de $80 \%$ de acertos independentes (sem dicas ou ajudas).

\section{Sonda de Aprendizagem com Frações Não Unitárias}

Ao final do procedimento de ensino de frações não unitárias, foram realizadas 25 tentativas como sondas de aprendizagem. Na primeira tentativa foi utilizado o material Círculo de Frações Adaptado e o participante deveria entregar dois terços de três peças ao pesquisador.

Da $2^{\mathrm{a}}$ a $7^{\mathrm{a}}$ tentativa foi utilizado o material Escala Cuisenaire. $\mathrm{Na}$ segunda tentativa foram usadas 10 peças, sendo solicitado que o participante entregasse três quintos das peças. Nas tentativas 3 e 4 foram solicitados cinco sextos e dois terços de 12 peças, respectivamente. Nas tentativas 5, 6 e 7 foi solicitado que fossem entregues, respectivamente, quatro quintos de 15 peças, três quartos de 16 peças e dois terços de 18 peças.

$\mathrm{Na}$ oitava tentativa foram utilizadas bolinhas de gude, sendo solicitado que o participante entregasse três quartos de oito peças. Em seguida, na tentativa 9, foi solicitado que o participante entregasse dois terços de nove peças.

Nas tentativas 10,11,12, 13 e 14 foi utilizado o Círculo de Frações Adaptado. Na tentativa 10 foi solicitado que o participante entregasse três quartos de quatro peças. Nas tentativas 11, 12 e 13 foi solicitado dois quintos, três quintos e quatro quintos de cinco peças, respectivamente. $\mathrm{Na}$ tentativa 14 foi solicitado que fosse entregue três quartos de oito peças.

Nas tentativas 15, 16, 17, 18 e 19 foi utilizado o material Monta Fácil. Na tentativa 15 foi solicitado que o participante entregasse dois terços de seis peças. Nas tentativas 16 e 17 foi solicitado que ele entregasse três quartos de oito peças e três quintos de 10 peças. Nas tentativas 18 e 19, usando 12 peças, foi solicitado que o participante entregasse, respectivamente, dois terços e três quartos das peças para o pesquisador.

Por fim, nas tentativas 20, 21, 22, 23, 24 e 25 foi usado o material Monta Fácil Encaixado e foi solicitado que o participante entregasse, respectivamente, três quartos de oito peças e dois terços de nove peças, dois quintos e quatro quintos de 10 peças, três quartos de 12 peças e três quartos de 16 peças.

\section{Cálculo de Índice de Fidedignidade}

Para o cálculo do índice de fidedignidade, $20 \%$ das videogravações das sessões foram examinados por um observador independente que categorizou as respostas de interesse. Os resultados obtidos pelo observador foram cotejados com aqueles produzidos pelo pesquisador, 
sendo assinaladas as concordâncias e as discordâncias. Segundo Fagundes (1999), são considerados fidedignos se houver concordância de, no mínimo, $80 \%$, segundo a fórmula:

$$
\text { Concordâncias }=\frac{\left(\mathrm{N}^{\mathrm{o}} \text { de concordâncias }\right)}{\left(\mathrm{N}^{\mathrm{o}} \text { de concordâncias }+\left(\mathrm{N}^{\mathrm{o}} \text { de discordâncias }\right)\right.} \quad * 100
$$

O índice obtido foi de $93 \%$ de concordância entre pesquisador e observador independente.

\section{Resultados}

Os três participantes foram expostos às tarefas para identificarem igualdade e diferença e frações unitárias de metade e um terço em tentativas de escolha de acordo com o modelo atrasado. Nessa etapa inicial, os três participantes acertaram todas as cinco atividades propostas.

Os resultados foram organizados para cada participante e consideraram-se as frações unitárias e as frações não unitárias, nessa ordem.

\section{Pa18}

\section{Frações Unitárias}

$\mathrm{Na}$ etapa do levantamento de repertório de entrada com fração de meio e um terço, Pa18 errou a tentativa em que era solicitado um terço de seis peças. A participante alcançou o critério de desempenho na fase de intervenção com frações unitárias em quatro encontros.

A Figura 2 apresenta o desempenho de Pa18 na linha de base - L. B. (repertório de entrada), na fase de ensino (Encontros de 1 a 4), na sonda de aprendizagem e no follow up com frações unitárias.

Figura 2 - Desempenho da Participante Pa18 ao longo do experimento - Frações Unitárias

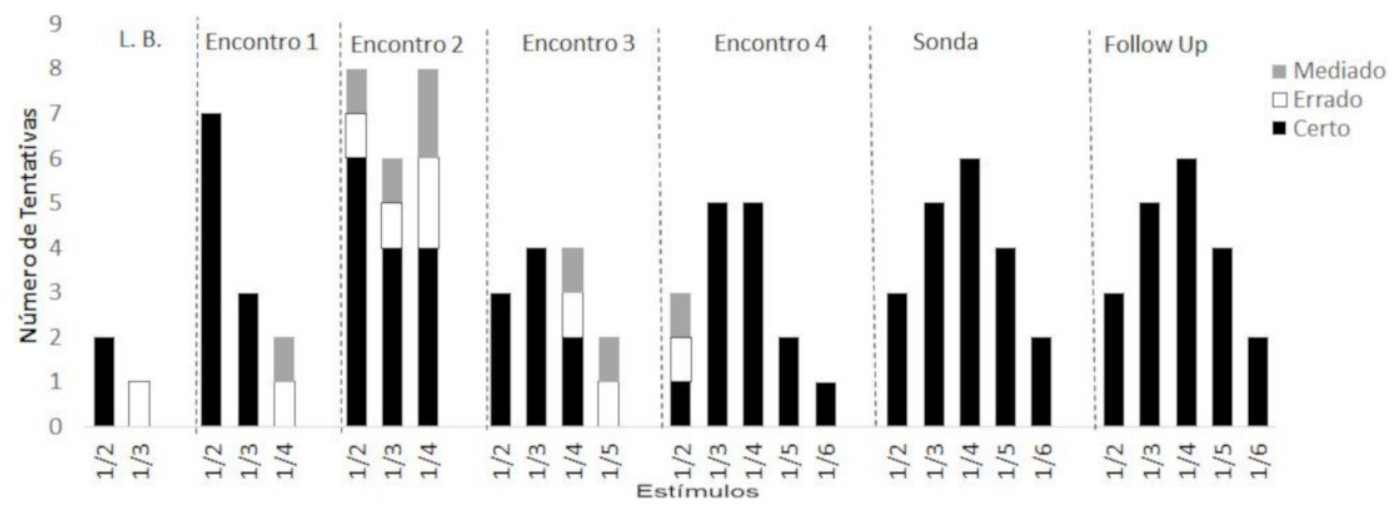

Fonte: elaborado pelos autores. 
Nos dois encontros iniciais da aplicação do procedimento de ensino, os erros de Pa18 ocorreram, na maioria das vezes, em tentativas em que havia quantidades superiores a oito peças. Porém, nos encontros finais, esses erros não apareceram mais. Nas nove tentativas em que ocorreram erros $(1 / 4$ de $8,1 / 3$ de $12,1 / 4$ de $8,1 / 2$ de $12 ; 1 / 4$ de $12,1 / 4$ de $8,1 / 5$ de $15,1 / 4$ de $8,1 / 2$ de 8 ), ao longo dos quatro encontros, a mediação do pesquisador com o procedimento de correção de erros foi suficiente para que o acerto ocorresse com sucesso.

$\mathrm{Na}$ sonda de aprendizagem e no follow up com frações unitárias, Pa18 obteve 100\% de acertos (21 acertos em 21 tentativas).

\section{Frações Não Unitárias}

A Figura 3 apresenta o desempenho de Pa18 nas atividades de ensino e na sonda de aprendizagem com frações não unitárias.

Figura 3 - Desempenho da Participante Pa18 ao longo do experimento - Frações Não Unitárias

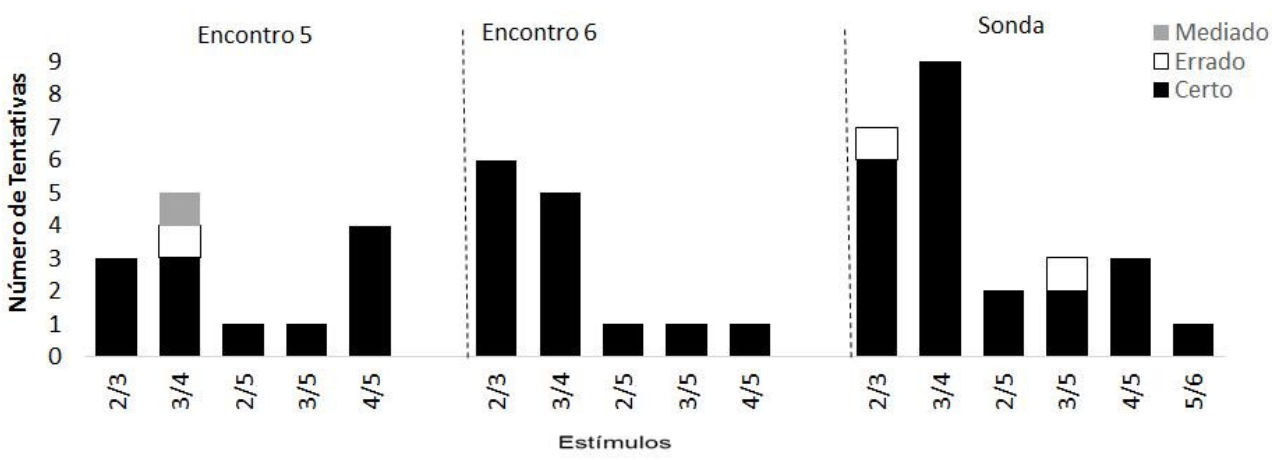

Fonte: elaborado pelos autores.

Pa18 alcançou o critério de desempenho no ensino com frações não unitárias em dois encontros, cometendo somente um erro em um total de 28 tentativas. Na sonda de aprendizagem com frações não unitárias, Pa18 cometeu dois erros em tentativas com barras da escala Cuisinaire.

\section{Po14}

\section{Frações Unitárias}

A Figura 4 apresenta o desempenho de Po14 na linha de base - L. B. (repertório de entrada), na fase de ensino (Encontros de 1 a 3), na sonda de aprendizagem e no follow up com frações unitárias. 
Figura 4 - Desempenho da Participante Po14 ao longo do experimento - Frações Unitárias

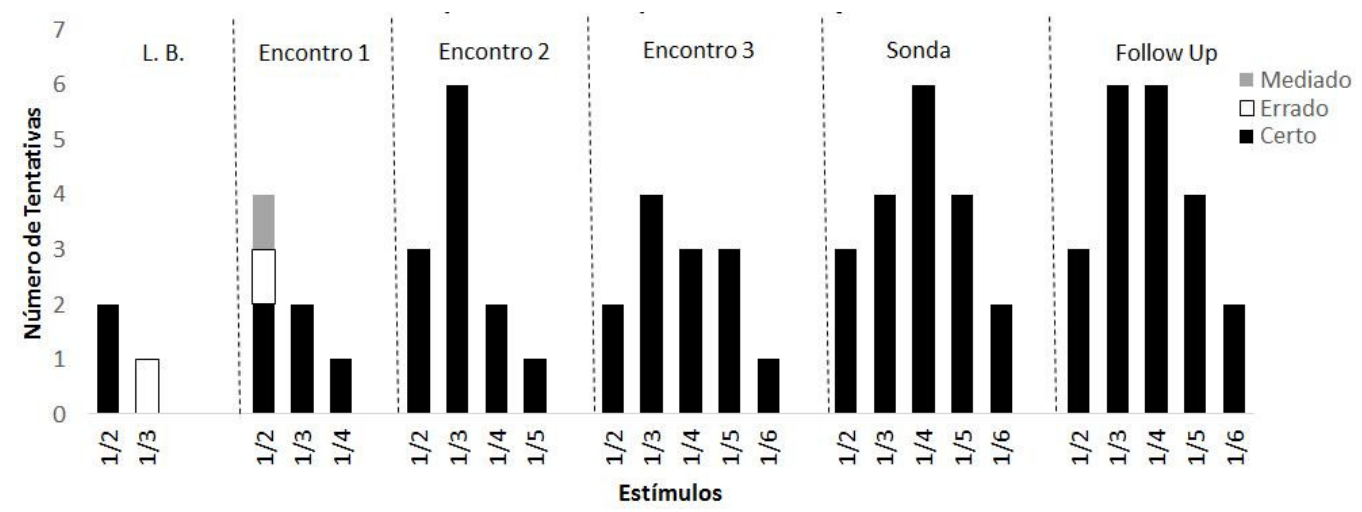

Fonte: elaborado pelos autores.

$\mathrm{Na}$ linha de base com tarefas que envolviam frações de meio e um terço, Po14 errou a tentativa em que era solicitado um terço de seis peças. Po14 alcançou critério de aprendizagem em três encontros, tendo cometido um erro no primeiro encontro. $\mathrm{Na}$ sonda de aprendizagem e no follow up com frações unitárias Po14 acertou todas as tentativas.

\section{Frações Não Unitárias}

A Figura 5 apresenta o desempenho de Po14 nas atividades de ensino, na sonda de aprendizagem com frações não unitárias.

Figura 5 - Desempenho da Participante Po14 ao longo do experimento - Frações Não Unitárias

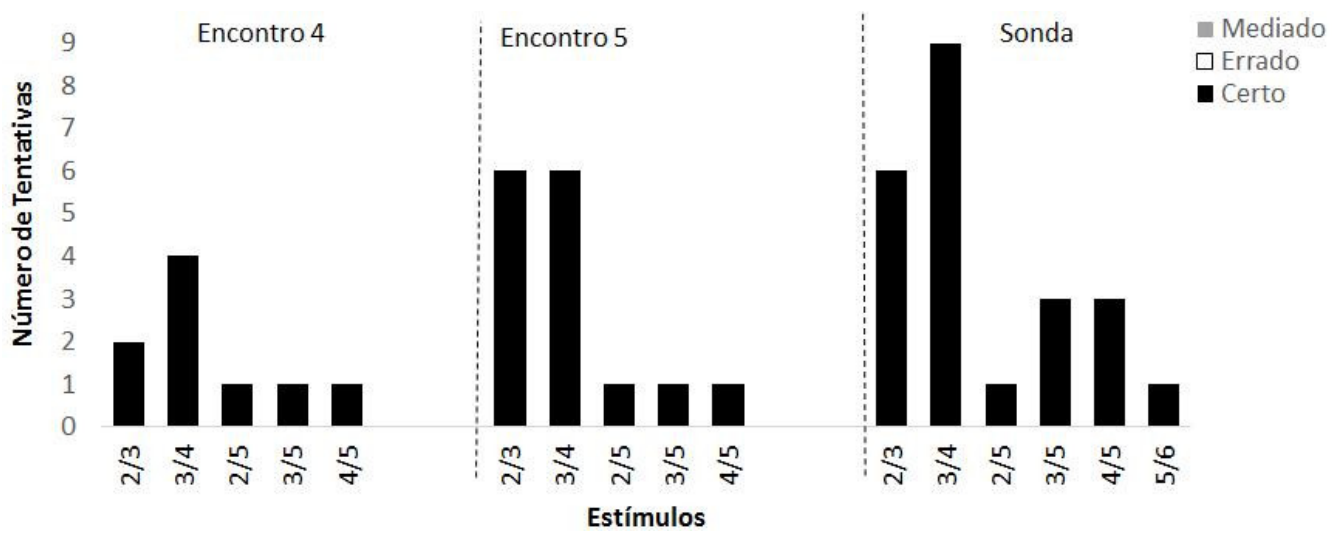

Fonte: elaborado pelos autores. 
Nota-se, na Figura 5, que Po14 alcançou critério de desempenho nos blocos com frações não unitárias em dois encontros, não cometendo erro nestes encontros. $\mathrm{Na}$ sonda de aprendizagem com frações não unitárias Po14 também não cometeu erros.

\section{Po16}

\section{Frações Unitárias}

A Figura 6 apresenta o desempenho de Po16 na linha de base - L. B. (repertório de entrada), na fase de ensino (Encontros de 1 a 4), na sonda de aprendizagem e no follow up com frações unitárias.

Figura 6 - Desempenho de Po16 ao longo do experimento - Frações Unitárias

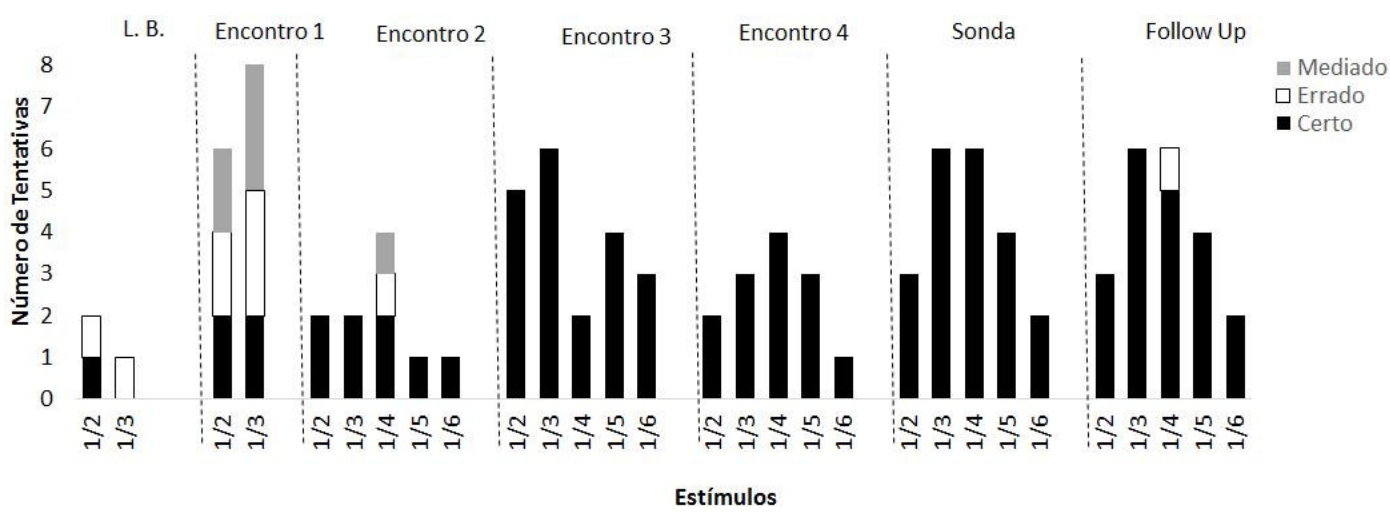

Fonte: elaborado pelos autores.

$\mathrm{Na}$ fase de linha de base com blocos que envolviam frações de meio e um terço, Po16 errou uma tentativa em que era solicitada a metade de quatro peças e um terço de seis peças. Em quatro encontros, Po16 alcançou critério de desempenho para as tarefas de frações unitárias. Os erros de Po16 ocorreram principalmente no primeiro encontro, indicando dificuldade em responder sob controle, das frações de metade e um terço ou em função da novidade da tarefa. No segundo encontro, ocorreu somente um erro, na presença de uma nova fração (um quarto). Entretanto, imediatamente após a apresentação do procedimento de correção, o participante respondeu corretamente às tentativas reapresentadas.

No terceiro e quarto encontro, na sonda de aprendizagem, Po16 acertou todas as tentativas. No follow up, Po16 cometeu um erro na tarefa de fração de um quarto.

\section{Frações Não Unitárias}

A Figura 7 apresenta o desempenho de Po16 na linha de base, nas atividades de ensino e na sonda de aprendizagem com frações não unitárias. 
Figura 7 - Desempenho de Po16 ao longo do experimento - Frações Não Unitárias

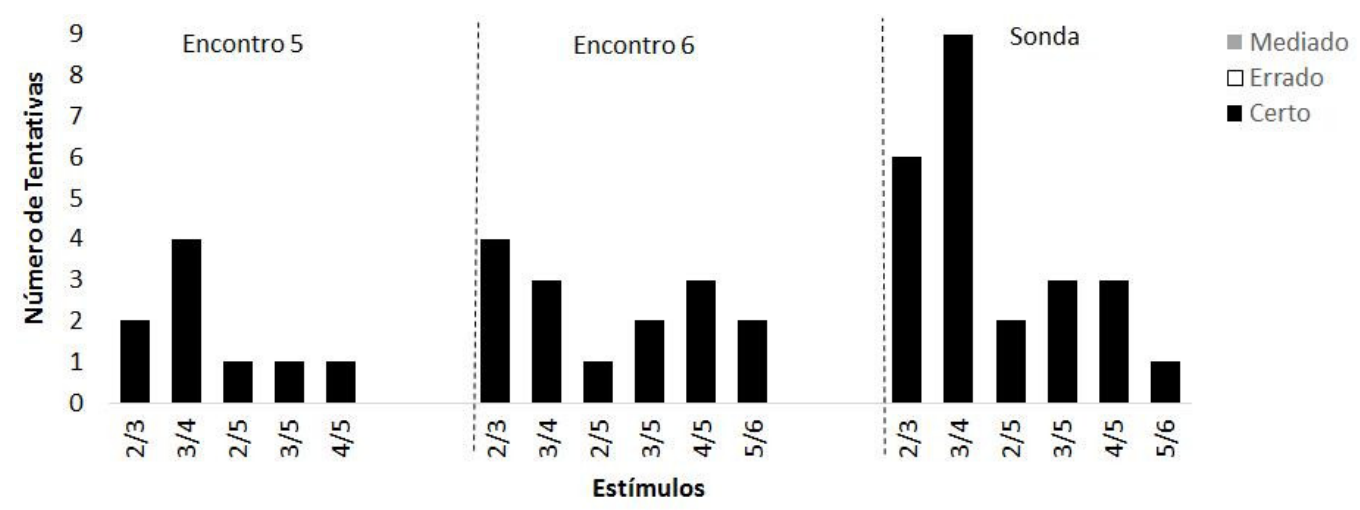

Fonte: elaborado pelos autores.

Po16 alcançou critério de desempenho com frações não unitárias em dois encontros, não cometendo nenhum erro. $\mathrm{Na}$ sonda de aprendizagem com frações não unitárias, Po16 também não cometeu erros.

Não ocorreu a aplicação das atividades do follow up com as tarefas de frações não unitárias com Po16 devido ao final do ano letivo.

\section{Discussão}

Os dados do levantamento de linha de base mostraram que os participantes identificaram igualdade e diferença, bem como metade de quatro e seis peças, mas não identificaram um terço de seis peças.

De maneira geral, nos dois primeiros encontros de ensino de frações unitárias, os participantes tiveram dificuldades em resolver as tentativas, ocorrendo erros em parte das atividades de metade, um terço e um quarto e somente Pa18 cometeu um erro com a fração de um quinto no terceiro encontro. Nos encontros seguintes, entretanto, os erros não aconteceram e foram fortemente reduzidos na sonda de aprendizagem e no follow up (exceto Pa18 que cometeu um erro no quarto encontro e Po16 cometeu um erro no follow up). Na fase de ensino com frações não unitárias, apenas Pa18 cometeu dois erros, um na fase de ensino e um na sonda de aprendizagem. Esses dados sugerem que o reforçamento de respostas corretas e, consequentemente, da cadeia de comportamentos para resolver cada problema (raciocínio) na presença de algumas frações, foi suficiente para emissão de respostas corretas na presença de novas frações no decorrer da aplicação do procedimento. Segundo Martin e Pear (2009), uma cadeia comportamental pode ser definida como uma sequência de estímulos discriminativos $\left(\mathrm{S}^{\mathrm{D}}\right)$ e respostas em que cada resposta, exceto a última, produz o $\mathrm{S}^{\mathrm{D}}$ para a próxima resposta e somente a última resposta produz o reforço que fortalece e mantem toda a cadeia.

Frente aos resultados pode-se inferir que ocorreram respostas generalizadas pela interpretação das tarefas de frações (LOPES, 2008) demonstradas pelo responder semelhante 
diante de novos estímulos e no responder discriminado na presença de estímulos diferentes nas diversas atividades com materiais contáveis, contribuindo para o desenvolvimento do raciocínio abstrato (CANOVAS, 2010). Portanto, pode-se sugerir, com base nos resultados, que os participantes interpretaram o conceito de fração como parte-todo, uma vez que foi solicitado separar parte de um conjunto de elementos.

Outro aspecto avaliado foi a utilização do recurso da linguagem durante a realização das atividades, que foi introduzido para a discriminação dos objetos e para a integração das informações provenientes dos sentidos preservados, detalhando as pistas visuais aos participantes (LEWIS, 2003). Essa, por sua vez, também foi utilizada como dica verbal descritiva feita sempre que o participante cometia um erro, oferecendo condições para a elaboração das respostas, dando ao aprendiz o suporte na descrição do que está acontecendo e propondo desafios ao raciocínio do participante. Esse procedimento de correção de erros obteve êxito em todas as oportunidades em que foi aplicado.

A partir disso, concluiu-se que o estudo obteve sucesso no emprego das atividades de ensino de frações através da linguagem, bem como na mediação oferecida aos participantes.

Em relação aos materiais utilizados no estudo, fica indicada sua eficácia para a avaliação do repertório para a aprendizagem de tais tarefas para os participantes com deficiência visual. De maneira geral, seu emprego nas atividades de ensino obteve êxito, atingindo o objetivo proposto por Del Campo (1996), que é a adequada transposição das formas visuais ao tato, uma vez que os participantes não tiveram dificuldades no seu manuseio e reconhecimento pela via tátil, conforme indicado pelo autor.

\section{Considerações Finais}

Por fim, pode-se dizer que o objetivo geral da pesquisa foi atingido com o emprego dos procedimentos de ensino de tarefas que envolviam frações unitárias e não unitárias para adolescentes com deficiência visual, podendo também ser empregado com adolescentes com o sistema sensorial visual íntegro.

O estudo mostrou que é viável ensinar frações aos alunos com deficiência visual usando materiais concretos simples ou adaptados. Outra implicação refere-se ao papel da linguagem no ensino que pode ser empregada com sucesso na discriminação de objetos e na correção de erros cometidos durante cada atividade, como meio de antecipação e de descrição de cada situação de ensino a esses alunos. Em particular, o estudo forneceu um bom exemplo da eficácia de um procedimento de ensino de frações aos alunos com deficiência visual.

Estudos futuros poderiam aplicar blocos mais extensos e com diferentes frações em linha de base para identificar com mais acurácia o repertório de entrada. Adicionalmente, estudos futuros poderiam ser expandidos para o uso de materiais não contáveis, nos quais a dimensão do estímulo estaria baseada em volume, como a seleção de partes fracionárias de volumes pequenos de massa de modelar. 


\section{Agradecimentos}

Os autores agradecem às seguintes agências de fomento à pesquisa: o primeiro autor contou no mestrado com bolsa de estudos e apoio da Coordenação de Aperfeiçoamento de Pessoal de Nível Superior (CAPES), processos 967.458 e 88887.136407/2017-00; Conselho Nacional de Desenvolvimento Científico e Tecnológico (CNPq), processo 465686/2014-1; Fundação de Amparo à Pesquisa do Estado de São Paulo (FAPESP), processo 2014/50909-8, em suporte ao Instituto Nacional de Ciência e Tecnologia sobre Comportamento, Cognição e Ensino (INCT-ECCE).

\section{Referências}

BRASIL. Ministério da Educação. Diretrizes curriculares nacionais para a educação infantil. Brasília: MEC, 2010.

BRASIL. Ministério da Educação. SAEB: sistema de avaliação da educação básica: evidências da edição de 2017. Brasillia: MEC, 2018.

CANOVAS, D. S. Discriminações simples simultâneas e sucessivas na formação de classes funcionais. 2010. 132 f. Dissertação (Mestrado em Ciências Humanas) Universidade Federal de São Carlos, São Carlos, 2010.

CARMO, J. S. O conceito de número como rede de ligações. In: KERBAUY, R. R. (org.). Sobre comportamento e cognição vol. 5: conceitos, pesquisa e aplicação, a ênfase no ensinar, na emoção e no questionamento clínico. Santo André: SET, 2000. p. 97-113.

DEL CAMPO, J. E. F. La enseñanza de la matemática a los ciegos. Madrid: Organización Nacional de Ciegos Españoles, 1996.

DEL REY, D. Análise do comportamento no Brasil: o que já foi pesquisado até 2005 em relação aos comportamentos matemáticos. 2009. 95 f. Dissertação (Mestrado em Psicologia Experimental) - Pontifícia Universidade Católica de São Paulo, São Paulo, 2009.

FAGUNDES, A. J. F. M. Definição, descrição e registro do comportamento. 12. ed. São Paulo: EDICON, 1999.

FERNANDES, S. H.; HEALY, L. A inclusão de alunos cegos nas aulas de matemática: explorando área, perímetro e volume através do tato. Bolema, Rio Claro, v. 23, n. 37, p. 1111-1135, 2010.

HAYDU, V. B.; COSTA, L. P. D.; PULLIN, E. M. M. P. Resolução de problemas aritméticos: efeito de relações de equivalência entre três diferentes formas de apresentação dos problemas. Psicologia: reflexão e crítica, Porto Alegre, v. 19, n. 1, p. 44-52, 2006.

HENKLAIN, M. H. O.; CARMO, J. S.; HAYDU, V. B. Produção analítico-comportamental brasileira sobre comportamento matemático e de ensinar matemática: dados de 1970 a 2015. Temas em Psicologia, Ribeirão Preto, v. 25, n. 3, p. 1453-1466, 2017.

HOCHMAN, B.; NAHAS, F. X.; OLIVEIRA FILHO, R. S.; FERREIRA, L. M. Desenhos de pesquisa. Acta Cirúrgica Brasileira, São Paulo, v. 20, sup. 2, p. 2-9, 2005. 
KAPPERMAN, G.; STICKEN J. A software tutorial for learning the Nemeth code of braille mathematics. Journal of Visual Impairment \& Blindness, Thousand Oaks, v. 96, n. 12, p. $855-57,2002$.

KLINGENBERG, O. G.; FOSSE, P.; AUGESTAD, L. B. An examination of 40 years of mathematics education among Norwegian braille-reading students. Journal of Visual Impairment \& Blindness, Thousand Oaks, v. 106, n. 2, 2012.

LEWIS, V. Development and disability. Oxford: Blackwell, 2003.

LOPES, A. J. O que nossos alunos podem estar deixando de aprender sobre frações, quando tentamos lhes ensinar frações. Bolema, Rio Claro, v. 21, n. 31, p. 1-21, 2008.

MANI, M. N. G.; PLERNCHAIVANICH, A.; RAMESH, G. R.; CAMPBELL, L. Mathematics made easy for children with visual impairments. Philadelphia: Overbrok School for the Blind, 2005.

MARTIN, G.; PEAR, J. Modificação de comportamento: o que é e como fazer. 8. ed. São Paulo: Roca, 2009.

NUNES, A. L. M.; ASSIS, G. J. A. Emergência de classes ordinais após o ensino de relações numéricas. Revista Brasileira de Análise do Comportamento, Belém, v. 2, n. 2, p. 203-2019, 2012.

OLIVEIRA, R. Aprendizagem de frações: uma análise comparativa de dois processos diferentes de ensino na $5^{\mathrm{a}}$ série do $1^{\circ}$ grau. 1996. 178 f. Dissertação (Mestrado em Educação) - Faculdade de Educação, Universidade Estadual de Campinas, Campinas, 1996.

REILY, L. Escola inclusiva: linguagem e mediação. Campinas: Papirus, 2004.

RIBEIRO, M. P. L.; ASSIS, G. J. A.; ENUMO, S. R. F. Comportamento matemático: Relações ordinais e inferência transitiva em pré-escolares. Psicologia: teoria e pesquisa, Porto Alegre, v. 23, n. 1, p. 25-32, 2007.

ROSENBLUM, L. P.; HERZBERG, T. Accuracy and techniques in the preparation of mathematics worksheets for tactile learners. Journal of Visual Impairment \& Blindness, Thousand Oaks, v. 105, n. 7, p. 402-413, 2011.

SANTOS, A. C. G.; SIMONASSI, L. E.; RODRIGUES, C. F.; MAGRI, M. R. Efeito do treino de composição (cópia) na aprendizagem do conceito de proporção. Psicologia: teoria e pesquisa, v. 30, n. 4, p. 459-469, 2014.

SANTOS, R. F.; SAMPAIO, P. Y. S.; SAMPAIO, R. A. C.; GUTIERREZ, G. L.; ALMEIDA, M. A. B. Tecnologia assistiva e suas relações com a qualidade de vida de pessoas com deficiência. Revista de Terapia Ocupacional da Universidade de São Paulo, São Paulo, v. 28 , n. 1 , p. 54-62, 2017. 
SILVA, A. F. G.; CANOVA, R. F.; CAMPOS, T. M. M. A fração em livros didáticos de matemática para os anos iniciais. Acta Scientiae, Canoas, v. 18, n. 1, p. 41-54, 2016.

SKINNER, B. F. Tecnologia do ensino. São Paulo: Herder, 1972.

TRASK-TYLER, S. A.; GROSSI, T. A.; HEWARD, W. L. Teaching young adults with developmental disabilities and visual impairments to use tape-recorded recipes: acquisition, generalization, and maintenance of cooking skills. Journal of Behavioral Education, New York, v. 4, n. 3, p. 283-311, 1994.

VERNEQUE, L. Aprendizagem de frações equivalentes: efeito do ensino de discriminações condicionais minimizando o erro e da possibilidade de consulta a dicas. 2011. 117 f. Tese (Doutorado em Ciências do Comportamento) - Instituto de Psicologia, Universidade de Brasília, Brasília, 2011. 
